
prior permission. Violators will be prosecuted.

\title{
Auditive stimulation of dance accompaniment in the Sekar Kinanti art studio as a method of increasing kinesthetic intelligence
}

\author{
G.K.W. Anggraheni, K.S. Astuti, A. Husna \& W.O. Wiko \\ State University of Yogyakarta, Yogyakarta, Daerah Istimewa Yogyakarta, Indonesia
}

\begin{abstract}
Auditive stimuli focus works through using sounds or voices to stimulate creativity. Auditive stimulation is one of the initial stimuli in dance while auditive stimuli is one of the new methods to develop one's creativity in dance. The Sekar Kinanti Art Studio (SSKS) in Yogyakarta, Indonesia uses auditive stimulation methods to support the learning process. This research is a descriptive, qualitative study that reveals the progression of events that occur in the SSKS, and in particular investigates the learning methods used in the studio. As part of the learning process in SSKS auditive stimulation methods successfully shape the studio students' kinaesthetic abilities. Kinaesthetic abilities (motion and the sense of motion) is observed in SSKS graduates who have passed the learning process after a period of two to five years in the SSKS. Auditive stimulation is one method implemented to help form one's kinesthetic abilities.
\end{abstract}

\section{INTRODUCTION}

The essence of music is sound. Sound can come from the natural voice. Humans as part of nature, have feelings (senses) toward rhythm. Millions of sounds in nature are processed by humans into music. Psychologically, music is a product of the mind. Basically, music elements such as vibration, frequency and duration cannot be said to be "music" if these elements have not been transformed neurologically and then interpreted by the brain into pitch, timbre, tempo, and dynamics (Djohan, 2009, p. 32).

In its development, music has two main functions: as a means of nemesis and as catharsis (soul purification). Music as a media nemesis is shown in sixteenth century opera performances where music can be an emotional reflection of the human condition. The function of music as a means of catharsis is believed to be a medium for expressing oneself. Music helps to shape, organise and deliver emotions while media trains inspiration. In a specific cultural context, music has more complex functions. Music is present in every aspect of people's lives such as for ceremonies related to marriage, death and birth, as well as religious ceremonies, rituals, traditional activities and dances (Djohan, 2009, pp. 87-88). Music and dance are two sides of a whole that are difficult to separate from each other. In dance performances, music is one of the elements that must exist. Music in dance functions to regulate emotions, motion, space and time, and inspiration in the dance. Hidajat (2008) states that music has three functions in choreography: 1) music as motion accompaniment; 2) music as an affirmation of motion; and 3) music as illustration.

Music as illustration presents or creates nuances underlying the events in a dance work, building the audience's perception to enter into the work, and is used by dancers as a medium that helps determine the movement and deepens the inspiration of the work.

Sensitivity to music is not immediately owned by dancers. Musical sensitivity can be trained using a variety of methods including stimulation. Auditive stimuli as one stimulus can present and increase kinaesthetic awareness (motion and sense of motion). As a basic concept, humans have a physical response while listening to various kinds of sounds. This basic concept was thus taken and applied by the Kinanti Sekar Art Studio (SSKS) as one of the studio's dance learning methods. 

prior permission. Violators will be prosecuted.

SSKS is one of dozens of dance studios in the Special Region of Yogyakarta that along with other studios, care about sustainability and the future life of art especially traditional arts. The SSKS offers three kinds of dance classes: classical dance class, creative dance class and children's dance class. The learning system in SSKS is new and unique because the system presents a method of responding to initial stimuli. One of the methods involves using audio stimulus to train the studio students' musical sensitivity (sedulur). Musical sensitivity is needed because the music or dance accompaniment used in the SSKS uses traditional collaborative music and modern EDM (Electronic Dance Music) in the MIDI (Musical Instrument Digital Interface) format. The transition between each bar in music is difficult for beginners to understand, so the ability to hear transitions needs to be trained early.

Understanding music is considered important for Kinanti Sekar Rahina, the owner of the Kinanti Sekar Art Studio. As music plays an important role in, for example, being able to count from one to eight in a dance work. During the learning process each facilitator (teacher) at the SSKS is encouraged to know and understand every detail of dance accompaniment music. During the process of delivering the dance material, the facilitator minimizes counting one to eight, and replaces this traditional way of teaching by instead imitating the music. In certain classes the facilitator will play music and the students are given the freedom to respond to the music they hear.

Based on the above-mentioned learning events that occurred at the SSKS, the researcher was interested in examining the role of auditive stimuli upon dance accompaniment at the Kinanti Sekar Art Studio as a method of increasing kinesthetic abilities. The accompaniment music that was studied are called motion dance music and songs for the Sekar Taji Mask dance in the child category called Kenes Gandhes dance music for new dance in the creative class category.

\section{METHODOLOGY}

This research is a descriptive, qualitative method study. Descriptive qualitative methods were chosen to explain the overall object of study in the research while the analysis refers to relevant theories. The data was collected by the researchers as key instruments for the investigation. The data was collected by observing and seeing the facts in the field, in various settings and with various methods and sources (Sugiyono, 2014, pp. 62-63). In this study, the data was obtained through observation, interviews, documentation and triangulation techniques.

The research took place at the the Kinanti Sekar Art Studio in Yogyakarta, Indonesia. The data was obtained by observing the learning process at the SSKS, by interviewing the studio owner, the management personnel, the dance class facilitator and others in the SSKS. Documentation studies are also part of research techniques that made it possible to read student documents from the beginning when the SSKS was first established and until this research was conducted.

\section{DISCUSSION}

\subsection{Auditive stimulation}

Stimulation, often referred to as stimulus, is a term used in psychology to explain something that provokes a certain response. Stimulation can trigger the appearance of behaviours or attitudes. Auditive stimulation is one of the elements found in the initial stimulus. Auditive stimuli include sounds that stimulate creativity. These sounds can come from musical instruments and music tapes. As for the sounds of nature and the environment, such as the sounds of waves, animals as well as various, frenzied sounds generated by human activities (Susanti, 201, p. 46).

In dance, auditive stimuli have a very big role. At the present, many dancers are inspired to move after listening to certain music, sounds or voices. In creating dance works, 

prior permission. Violators will be prosecuted.

choreographers can use auditive stimuli to stimulate the emergence of new movements in accordance with the theme of the choreographer's work. In modern dance learning, auditive stimuli are used as a method to hone one's kinesthetic creativity.

\subsection{Kinanti Sekar Art Studio}

The Kinanti Sekar Art Studio was founded on 24 July 2015. The SSKS has four kinds of classes: 1) classic dance class consisting of the Nawung Sekar dance, the Golek Ayun-Ayun dance and the Golek Kenya Tinembe dance; 2) creative dance class consisting of the Kenes Gandhes dance, the Gelegar Nusantara dance, the Sonteng dance and the Pendet dance; 3) children's dance class consisting of dance and song, the Kwek-Kwek dance, the Nyawiji dance, the Padhang Bulan dance and the Nusantara Anak dance; and 4) Kinari class, an advanced class for children that is specifically open to advanced level students. Additionally, there is a forum for studio alumni called the Kinanti Dance Laboratory.

Dance material is delivered using the methods of imitating and responding. The imitation method is applied to all classes especially classical dance classes. In the children's classes and creative classes mimicking and responding methods are used simultaneously. Students in the Sedulur studio are trained to respond to initial stimuli such as kinaesthetic, touching, visual and auditive in order to cultivate kinaesthetic and auditive abilities that students possess. The focus of delivering dance material during children's classes and creative classes is to introduce and guide the development of sensitivity to dance accompaniment as well as understanding the dance itself. This sensitivity is needed because the music that accompanies dances taught at the studio is a combination of modern and traditional MIDI format. The modern music is EDM.

One of the most distinctive characteristics of EDM is the way in which it is producednamely, through the use of electronic technologies such as synthesizers, drum machine, sequencers, and samplers. Although increasingly common in popular music in general in recent years, these technologies have always formed the backbone of musical creation in EDM, in which traditional instrument or live vocal is the exception rather than the rule. (Butler, 2006, p. 33)

For the process of making music with EDM, there are features that can be used to create traditional instrument sounds or other desired sounds. However, it is a difficult transition to distinguish sounds in EDM music in MIDI form. For beginners, the transition between cultivation in each bar of music is difficult to understand.

The style of music produced at the SSKS is different from music in other studios. Lay people (outside the SSKS) may not be able to dance with the music from the SSKS because the music has its own characteristics. In fact, students at the first level need time to adapt and get to know the dance accompaniment (Kinanti, personal communication, 3 September 2018). The absence of special cues for the transition of motion such as cues found in traditional music (gamelan), is an obstacle for beginning dancers making it challenging to determine the movements or changes in dance movements based on the SSKS music.

The children's classes use music that comes from children's songs such as the "Gugur Gunung" song for the Nyawiji dance, the "Padhang Bulan" song for the Padhang Bulan dance and a MIDI medley of nusantara music for the Nusantara Anak dance. The "Dolanan Anak" song was chosen as an arrangement material because the song is familiar to children and helps children to remember the music used in the dance.

For the learning process in creative classes body formation and musical sensitivity are prioritised. The class facilitator provides the basics of dance at the beginning of the class session and gradually over time trains the students' musical sensitivity. The method used is listening to the selected piece of music repeatedly and students are also asked to move according to what they hear. Repeating the material up to seven times in one class session is one way to make students listen to and recognize dance music. 


\section{Printing is for personal, private use only. No part of this book may be reproduced or transmitted without publisher's}

prior permission. Violators will be prosecuted.

In addition to regular classes, the SSKS has natural class programs as a dance learning support program. The natural class vision and mission is to invite all students at the SSKS to learn and interact with nature. The concept of auditive stimuli is actually implemented during this activity where students will explore what they hear and visualize what they hear through motion.

\subsection{Kinaesthetic intelligence}

Intelligence can be interpreted as an expression of ways of thinking that are used as modalities in learning. A theorist on intelligence named Gardner (1993), describes nine intelligences possessed by humans: linguistic intelligence, mathematical logic intelligence, spatial intelligence, musical intelligence, interpersonal intelligence, intra personal intelligence, naturalist intelligence, spiritual intelligence and physical or kinaesthetic intelligence (Khasanah, 2016). Gardner (1993) argues that kinaesthetic intelligence is the ability of a person to use his or her entire body or a part of the body to solve problems.

Kinesthetic intelligence can also be interpreted as possessing good coordination between the nerves, mind and limbs.Kinaesthetic intelligence or physical intelligence is the ability for a person to use his or her limbs to organise movements into activities such as running, dancing, building something, doing art activities or cubits works

The core component of kinaesthetic intelligence is the ability to use specific physical abilities of coordination, balance, skills, strength, flexibility, speed and ability to receive stimuli (proprioceptive) and is also related to tactile and haptic abilities or touch (Yuningsih, 2015).

\subsection{Auditive stimuli at the Kinanti Sekar Art Studio: Dance accompaniment music as a method of improving kinaesthetic intelligence}

The method of imitating and responding used a the SSKS is used to train young people to not only know how to dance but to also have good kinaesthetic abilities by responding to kinaesthetic stimuli, visual stimuli, touch stimuli and auditive stimuli. The body's responses to these stimuli is extended through exploration and presentation of motion.

Auditive stimulation is one method that is always used at the SSKS. Auditive stimulation is a process of searching for motion through audio. In dance this concept is used by choreographers to create works by referring to what is heard, producing work patterns by considering auditive aspects related to the body's ability to visualise what it hears (Hidajat, 2011, p. 95). Responses to various stimuli is a skill that is very important to introduce to student early in order to train creativity and the body.

By observing SSKS graduates researchers found that the SSKS implemented the following processes:

a. Systematic Learning System

The learning process at the SSKS is carried out by using the quarterly chess system. Competency testing is done at the end of the fourth month. The class facilitator manages 16 face-to-face sessions with the students to complete one dance material.

Based on observations made by the researchers since January 2016, the SSKS has graduated ten students from the creative dance class, three students from the classical dance class and one student from the Tembang class. Additionally, fourteen students from the children's Kinari class have also completed the qualification exam at the SSKS (Andi, personal communication, 30 July 2018).

b. Learning Support program

The learning support program at the SSKS consists of the nature class and the studio staff. The head of the studio, Andi Wicaksono, further described the two programs:

As the name implies, natural class is a visit to nature whether it's to the beach, mountains or rice fields. The purpose of the existence of a natural class is to introduce a studio in the surrounding environment that brings positive energy in our lives (humans). Sedulur is invited to unite with nature, learn in the open to accept whatever nature gives. Besides 


\section{Printing is for personal, private use only. No part of this book may be reproduced or transmitted without publisher's}

prior permission. Violators will be prosecuted.

that, SSKS has a studio program. Sowan in Javanese means visiting; Sowan sanggar means visiting other studios to establish friendship and sharing knowledge between studios. The hope of this activity is to know about the learning activities in other studios, and to exchange experiences in the arts and culture. (Andi, personal communication, 3 March 2018).

The research yielded results such as discovering interesting phenomena related to the dance learning system at the SSKS. During the last two years, the researchers observed five children's dance classes and five creative classes. The basic class for children is coded ' $a$ ', the first batch is coded A, the second batch is B, the third class is C, the fourth class is D and code $\mathrm{E}$ for the Kinari class. The first class of the creative category is coded as 1 , the second generation is 2 , the third class is 3 , the fourth class is 4 and the fifth class is coded as 5 .

The children's class with code ' $a$ ' is a dance class for 3 to 6-year olds. This class was only opened in the tenth class of the SSKS in August 2018. The material that is given is about motion and songs using the method of playing and moving. The application of the auditive stimulation method starts at this level where students are introduced to various kinds of dance accompaniment music, development music, children's songs and dancing with simple movements. The motion material that is given includes basic movements such as heating, that are arranged into a series of interesting movements according to the music that is used. The purpose of the movement and song class is for children to enjoy the learning process and assume that 'dancing is fun'.

The children's class that is coded A uses the dance material called Kwek-Kwek. This class is classified as a basis class for children who are 7 years old. Students are introduced to the basics of dance to be used at the next level. The movement in this dance aims to train the students' physical strength. Running, jumping and moving are the hallmark movements in this class. The facilitator has the responsibility to introduce complete traditional music by calculating each transfer. The facilitator uses the auditive stimulation method by repeatedly playing dance accompaniment while asking students to move to demonstrate the dance movements. If the motion carried out is not in accordance with the accompaniment or the student loses the count in the music, the facilitator repeats the activity from the beginning and is repeated until the student understands the key to transferring the music. In general, the students' kinesthetic abilities at this level was not observed. However, by the end and after the material has been given, there is an increase in dance skills by the students in class A.

The next level, called the Nyawiji class, is coded as B. At this level the students are given more complex dance material, both in terms of motion and music. Dance movements in the Nyawiji class are prioritized in a way so as to form and bring out the character of each student's body. During the learning process, the facilitator is the model for the students and occasionally the students alternately become models for each other. Realizing that music that has a high degree of difficulty for children, the facilitator uses the method of repeated listening so that the students can better know the accompaniment music. Improvements in the students' motion and musical sensitivity begins to appear at this level and the students tend to grasp material given by the facilitator more quickly. Each student's dance movements were observed as more organized at this level.

Next, students enter the Padhang Bulan class which is coded C. The music that is used has a faster tempo than the previous class, namely moderato (100-103). This music is intentionally used in class $\mathrm{C}$ to train the students' sensitivity to be able to respond to music with a fast tempo by adjusting to the music using existing dance moves. Based on observations, class $\mathrm{C}$ students have developed higher levels of musical and body sensitivity compared to the previous class.

The final level in the children's classes is called Nusantara Anak coded as D. This class is a fairly complex class such that students are introduced to dance forms from several regions in Indonesia. The dance accompaniment music is a medley of music consisting of nusantara songs that represent the area chosen by using EDM. Musical concentration and sensitivity are necessary to be able to understand the movements of dance accompaniment music. Based on the researchers' observations, these students developed stronger dancing skills. The student's 


\section{Printing is for personal, private use only. No part of this book may be reproduced or transmitted without publisher's}

prior permission. Violators will be prosecuted.

motion techniques experienced a significant increase; the form of motion began to look like 'waking' and organized. The ability of students to respond to the auditive stimuli of dance accompaniment music also showed a significant increase. Students were able to determine when to move based on the music they heard. Students found the 'code' for the movement of music so that dance movements were based on 'taste' in a simple sense. The ability to memorize dance movements and dance accompaniment music also increased compared to before. At level D, the level of kinesthetic abilities increased from class C.

Similar achievements were also seen in adult class students in the creative class. In the first stage in class 1 with Kenes Gandhes dance material, many students were getting to know dance for the first time in their lives. The dance material was given with a time duration that is not too long so that it would be easier for these students to memorise the dance movements and the music accompaniment. The music that is used is gamelan and EDM collaborative music. The Kenes Gandhes dance music is difficult because from the beginning to the end of the music there is no significant change in cultivation patterns. What is needed is repetition and that the intensity is not small to get into the accompaniment of dance music. For this reason, the class facilitators often use auditive stimulation methods to hone and develop the musical sensitivity of studio students.

The Level 2 goals for the Gelegar Nusantara dance material is to strengthen the musical and kinesthetic sensitivity of the studio. At this level, the material has a duration that is longer than Level 1. The purpose of this class is to introduce students to dance forms and movement of the Indonesian archipelago. Dance formation is emphasized at this level and indirectly, some students begin to see the forms of specific dances. The music in this class has a fairly high level of difficulty in grasping movement/music signs that serves as markers for certain dance movements and that require precision and high concentration. During the observation process, students found it easier to receive the material from the facilitator so that there were no special difficulties in delivering the dance material.

At Level 3, the students are exposed to complete dances from different regions. Examples of dances include the Pendet dance and the Sonteng dance. At this level 3 class, physical capabilities and the ability to identify music increase compared to levels 1 and 2 students. Students in level 3 more easily receive dance material because the ability to receive increases significantly. Likewise, musical sensitivity is at higher level when students are given the material. Generally speaking, the kinetic abilities of the SSKS students increased from one class level to the next as seen from the improvements in shape, technique, ability to respond to music creatively using the body while dancing.

For level 1 to 3 students, the graduation test is carried out by using dance material from levels 1 to 3 . One requirement that must be fulfilled by all SSKS students in the creative class is to create a dance work that departs from the dance materials given in the classes. Students who have passed the graduation test are coded 4 and 5. Based on the results of the study, the researchers observed that students in levels 4 and 5 had good body movements and could be said are not inferior to dancers from official dance institutions such as schools and dance arts universities. Student excellence at this level is the ability to create dance works. Creating dance works is not an easy thing to do, but the SSKS students are able to create dance works at a satisfactory level meeting the criteria for graduation from the studio.

Level 4 students create works that prioritise high sensitivity to music. Semicontemporary dance is chosen as a foothold in making dance works. The Prasapa dance work was created based on a variety of Yogyakarta-style movements and contemporary movements. The movements are those that are discovered by students while creating works in response to the four stimuli: kinesthetic, touch, visual and auditive. The results of this exploration then become the power of motion in the work that is being made. The music used to accompany this dance is made with the FL Studio application. Music to accompany dance works is made with the same pattern from beginning to end but occasionally uses tempo variations. The auditive excitement concept is seen in this dance accompaniment and is inspired by the learning process at the SSKS that uses auditive stimulation methods in creating dance movements. 

prior permission. Violators will be prosecuted.

To fulfill the graduation test, level 5 students also create dance works armed with the knowledge and experience gained during their studies at the SSKS. The work created is called Kekepetan dance that is made by developing motives and motion techniques acquired in the previous class. The music used in this work is EDM music.

In addition to level 4 and 5 students, there is another class where dance progress seems to increase. This is the Kinari class with code E where students have received all the material in the creative class and children's class. Kinari students are familiar with the learning methods carried out by Kinanti Sekar Rahina in the SSKS. The intensity of listening to the accompaniment music of a typical SSKS dance makes it possible for students to possess a high level of musical sensitivity. This sensitivity was observed in the Sekar Taji mask dance. The Kinari children's kinesthetic abilities was observed when responding to the music, which if heard does not have clear displacement or can be said to be contemporary music. A high level of kinesthetic intelligence makes it possible to perceive and interpret the beat of music and motion simultaneously even though the count is not clearly heard. This process is called 'ngrasakke', or feeling the meaning of the dance while performing, not just memorising the movements of the dance.

After reaching this stage, there were a lot of positive changes observed in the Kinari children. The biggest change was the growth in kinesthetic abilities. The children not only danced but were able to convey the meaning of the dance and delivered the meaning to the audience. To be categorized as a professional dancer is a bonus for Kinari students earned through the learning process. However, the main benefits are that children build a sense of solidarity, tolerance, responsibility, honesty, sportsmanship, family and togetherness.

\section{CONCLUSIONS}

The present era brings changes to dance learning systems. The method of delivering dance material is always developing every day. One development is responding to kinaesthetic, visual, touch and auditive stimuli.

The application of new methods to develop the ability to respond to stimuli is carried out to train the SSKS students' kinaesthetic abilities. In natural class programs, auditive stimuli are used as the main dance learning method where students are directed in such as way so as to be able to respond to the sounds of nature. Additionally, students are directed to create a simple work by responding to kinaesthetic stimuli, auditive stimuli and visual stimuli that exist in nature. This method is also used in regular classroom learning processes.

The use of this method at the SSKS produces students who have good bodily acumen, high musical sensitivity and optimal kinaesthetic abilities. As observed by the researchers, the SSKS graduates who have gone through the learning process for two years possess a form of dance that can be said to be equal to dancers graduating from formal institutions. The success of using the auditive stimulation method as a way to increase the level of kinaesthetic abilities can be seen in sedulur with codes C, D, E for child classes and codes 3, 4, and 5 for creative classes.

Thus, the learning method using auditive stimuli increase the level of kinaesthetic abilities. Auditive stimuli helps students develop kinaesthetic potential (motion and sense of motion) that is inherent in children. Using auditive stimuli makes the process easier for students to explore how to use their bodies. The ability to develop greater sensitivity and inspiration is enhanced using auditive stimuli.

\section{REFERENCES}

Butler, M.J. (2006). Unlocking the Groove: Rhythm, Meter, and Musical Design in Electronic Dance Music. Bloomington: Indiana University Press.

Djohan. (2009). Music Psikology. Yogyakarta: Best Publisher.

Gardner, H. (1993). Multiple Intelligences: The Theory in Practice. New York: Basic. 

prior permission. Violators will be prosecuted.

Hidajat, R. (2011). Choreography and Creativity. Yogyakarta: Media Kendil.

Khasanah, I. (2016). Enhancing Child Kinesthetic Intelligence through Angguk Traditional Dance at TK Melati II Glagah. Journal of Early Childhood Education, 5(3), 293.

Sudarsono. (1977). Indonesian Dances I. Jakarta: Proyek Pengembangan Media Kebudayaan Direktorat Jendral Kebudayaan, Departemen Pendidikan dan Kebudayaan.

Sugiyono. (2014). Understanding Qualitative Research. Bandung: Alfabeta.

Susanti, D. (2015). Application of Alma Hawkins Creation Method in Gundah Kancah Dance. Jurnal Ekspresi Seni. Institut Seni Isi Padangpanjang.

Yuningsih, R. (2015). Kinesthetic Intelligence Enhancement through Minang Dance Basic Motion Learning. Journal of Early Childhood Education, 9(2).

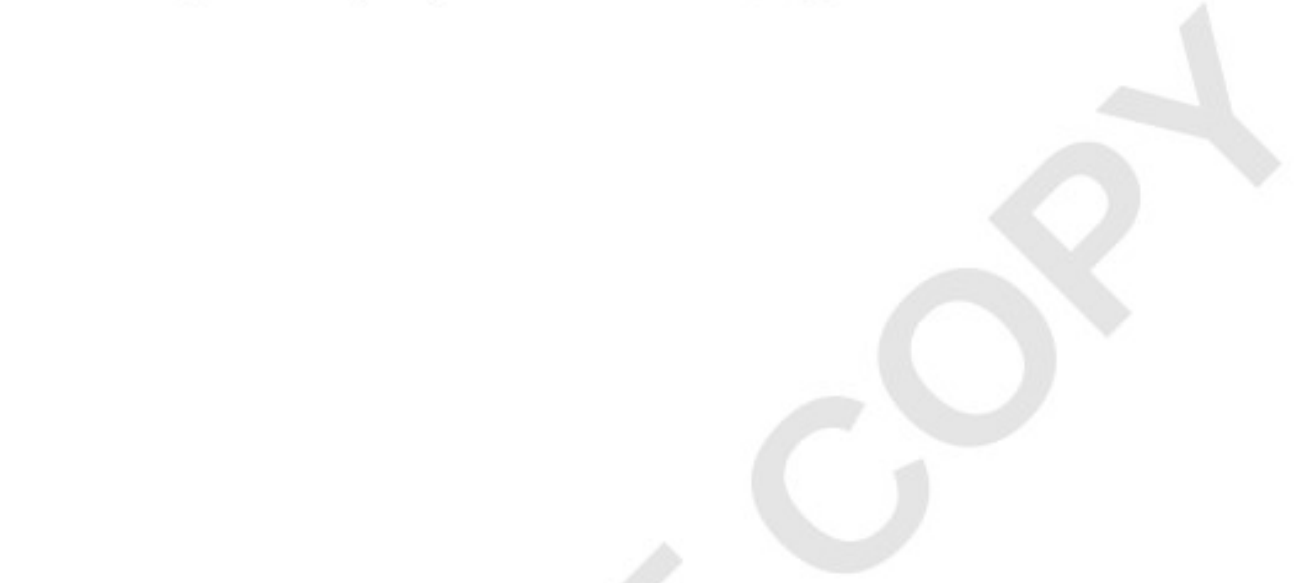

